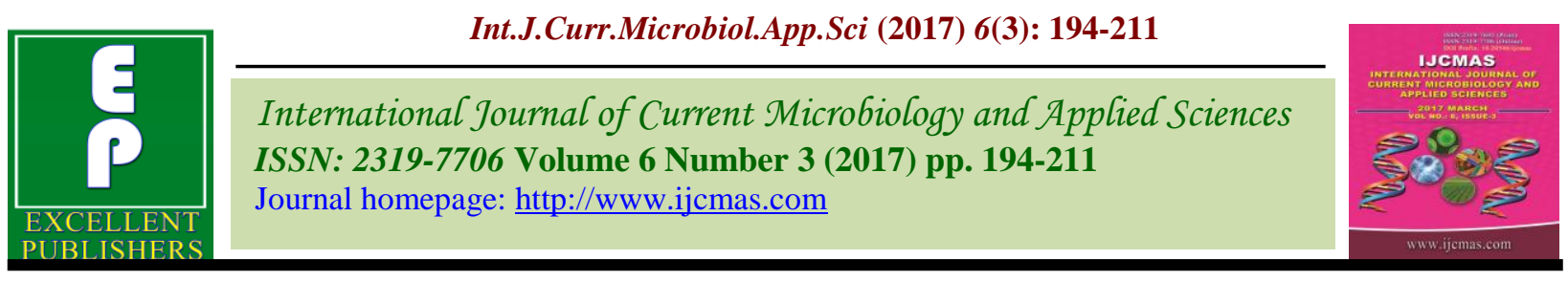

Original Research Article

https://doi.org/10.20546/ijcmas.2017.603.021

\title{
Antibiotic and Heavy Metal Tolerance of Some Indigenous Bacteria Isolated From Petroleum Contaminated Soil Sediments with A Study of Their Aromatic Hydrocarbon Degradation Potential
}

\author{
Jai Godheja ${ }^{1}$, Sudhir K. Shekhar ${ }^{1}$, G.N.V. Satyanarayan ${ }^{2}$, \\ Satyendra Pratap Singh ${ }^{3}$ and Dinesh Raj Modi ${ }^{1 *}$
}

${ }^{1}$ Department of Biotechnology, Babasaheb Bhimrao Ambedkar University, Lucknow, India
${ }^{2}$ Analytical Chemistry Section, Indian Institute of Toxicology Research, Lucknow, India
${ }^{3}$ Division of Plant Microbe Interactions, CSIR-National Botanical Research Institute,
Lucknow, India
*Corresponding author

\begin{tabular}{|c|c|}
\hline & A B S T R A C T \\
\hline $\begin{array}{l}\text { Bioremediation, } \\
\text { Bioaugmentation, } \\
\text { Benzene, Toluene, } \\
\text { Napthalene, } \\
\text { Acenapthene. }\end{array}$ & \multirow{3}{*}{$\begin{array}{l}\text { This article presents a study of the bacteria bioremediation characters and their heavy } \\
\text { metal and antibiotic tolerance from the petroleum contaminated soil located in } \\
\text { industrialized areas of Chhattisgarh, India. Soil sediments were characterized by FTIR for } \\
\text { the presence of aromatic compounds and further the heterotrophic and fuel degrader counts } \\
\text { was estimated. The strains characterized were predominantly from the Bacillus species } \\
\text { which showed mixed resistance patterns against antibiotics and heavy metals. The present } \\
\text { study results revealed that isolates Aneurinibacillus migulanus strain KTPP was most } \\
\text { potent in degrading all the hydrocarbons and showed multiple resistance against heavy } \\
\text { metals. Bacillus cereus strain BSP showed resistance against most heavy metals and also } \\
\text { was the second most active bacteria to degrade the selected hydrocarbons. All the isolates } \\
\text { except Bacillus cereus were resistance only to Penicillin G and Cefuroxime and sensitive } \\
\text { to others which shows that the transfer of antibiotic resistance genes has not taken place. }\end{array}$} \\
\hline Article I & \\
\hline $\begin{array}{l}\text { Accepted: } \\
\text { 08 February } 2017 \\
\text { Available Online: } \\
10 \text { March } 2017\end{array}$ & \\
\hline
\end{tabular}

\section{Introduction}

Production, refinery, transportation or storage of crude oil and its derivatives, through accidental leakages may lead to contamination of soils with BTEX compounds (benzene, toluene, ethyl-benzene and xylenes), polycyclic aromatic hydrocarbons (PAHs), as well as aliphatic hydrocarbons. Oil wells, petroleum plants, distribution and storage devices, transportation equipments are the main sources of the contaminations (Wolicka et al., 2009). Because trace heavy metals are common constituents of crude oil (Osuji and Onojake, 2004) and of petroleum derivatives $\left(\mathrm{Pb}^{2+}\right.$ leaded gasoline, lubricating oils and greases; $\mathrm{Zn}^{2+}, \mathrm{Cd}^{2+}$ compounds amended engine oil etc.) during an increased, long term pollution with hydrocarbons the heavy metal contamination of the respective areas should also be taken into account (John, 2007). Furthermore, within huge industrial areas (mining, metallurgical, oil distribution industry etc.) where hydrocarbon spills are very common the co-occurrence of hydrocarbon and heavy metal pollutants is observed (Abdullah et al., 2011).

All the above mentioned compounds in the environment cause serious health problems due to their carcinogenic and mutagenic 
effects (Mrozik and Piotrowska-Seget, 2009; Mishra et al., 2010). Because heavy metal and antibiotic resistance genes are often found on the same mobile genetic element, metal pollution often promotes the emergence of antibiotic resistances in exposed organisms, which fact has also a growing concern in natural and clinical settings (Knapp et al., 2011). Thus, the remediation of these sites has been of great interest.

Several treatment methods, applying physical, chemical and biological processes have been developed in the past decades. Physical and chemical approaches are capable of removing a broad spectrum of contaminants, but the main disadvantages of these methods lie in the increased energy consumption and the need of additional chemicals. Furthermore, with physico-chemical treatments, such as incineration, the transfer of pollutants from one environmental compartment to another may occur (e.g. from soil to atmosphere). During bioremediation, metabolic activity of micro-organisms is involved in breakdown of contaminants into non-toxic compounds. This technique is cost-effective, applicable over large areas and (usually) leads to the complete breakdown of the organic contaminants, potentially ending in their mineralization. Although bioremediation is a relatively time consuming process and the degree of success depends on a number of factors $(\mathrm{pH}$, temperature, availability of $\mathrm{O}_{2}$ and nutrients, etc.) aerobic bacterial biodegradation of aliphatic, simple aromatic hydrocarbons, like BTEX and low molecular weight PAHs is well characterized (Sarkar et al., 2004; Trindade et al., 2004).

As economic aspects are getting more considered in remediation processes, the more inexpensive bioremediation methods e.g. in situ biostimulation and bioaugmentation techniques are preferred. However, to evaluate the applicability of these bioremediation techniques in a petroleum hydrocarbon contaminated environment, it has to be known whether the microbial community of the contaminated environment has the metabolic potential to eliminate the contamination.

Due to the fact that Chhattisgarh has a notable oil collection centre, renowned steel production industries, aluminum production plants and power plants there is lot of hydrocarbon pollution around these industries. Since remediation of these sites is considerably costly, development of a microbial soil inoculant for bioaugmentation purposes could be an appropriate approach to treat the contaminated sites in Chhattisgarh. Therefore, the major goal of this study was to obtain a strain collection of hydrocarbonoclastic bacteria able to exert an outstanding degradation potential against high levels of hydrocarbon pollutants even within heavy metal impacted environments. In addition, our aim was to investigate and compare the diversity and activity of microbiota among two geographically closed petroleum hydrocarbon contaminated sites with different contamination characteristics using cultivation dependent and independent techniques. Furthermore, we determined the heavy metal tolerance and antibiotic resistance of isolated and identified aerobic hydrocarbon-degrading bacterial strains.

\section{Materials and Methods}

\section{Site description and soil sampling}

Soil samples were collected from ten different areas in Chhattisgarh (Table 1). The selected areas were from Raipur $\left(21.2514^{0} \mathrm{~N}\right.$, $\left.81.6296^{0} \mathrm{E}\right)$, Bhilai $\left(21.1938^{0} \mathrm{~N}, 81.3509^{0} \mathrm{E}\right)$, Bilaspur $\quad 22.076^{\circ} \mathrm{N}, \quad 82.139^{\circ} \mathrm{E}, \quad$ Korba $\left(22.3595^{\circ} \mathrm{N}, \quad 82.7501^{\circ} \mathrm{E}\right)$ and Raigarh $\left(21.8974^{0} \mathrm{~N}, 83.3950^{\circ} \mathrm{E}\right)$. 
Petroleum hydrocarbon contaminations (mainly diesel-oil and fuel oil) in all the cases resulted from spillages during distribution of the products from storage tanks. Samples were collected during the month of June. The top $15 \mathrm{~cm}$ of soil was collected using sterile spatula into sterile plastic bags for further transportation and microbiological analysis. Samples were stored at $4^{0} \mathrm{C}$ until further processing.

Soil $\mathrm{pH}$ of samples was determined by following the SR ISO 10390-1999 standard (Muntean and Rusu, 2011). Moisture content of soils (expressed in \%) was determined according to Damian et al., (2008); available potassium and organic carbon content was analyzed by Soil testing Kit (HiMedia) while the amount of phosphate and nitrate content was analyzed according to (Hooda and Kaur, 1999).

Estimation of total aerobic heterotrophic and hydrocarbon degrading germ count

Each soil sample $(10 \mathrm{~g})$ was dissolved in deionised water and kept to stand for 30 mins after vigorous shaking in sterile conditions. The sediments were collected and air dried for all the future experiments.

Aerobic heterotrophic and hydrocarbondegrading germ counts were estimated using the most probable number (MPN) method in 96 well microtiter plates, BBH (Bacto Bushnell Haas) mineral medium (HiMedia) by the method of Braddock and Catterall (2010), supplemented with tetrazolium violet (2,5-diphenyl-3-[alpha-napthyl] tetrazolium chloride) which is reduced to a dark purple colored derivative formazan on microbial respiration.

The results were obtained in the form of 7 dilution MPN series of each dilution factor and calculated as MPN/ gm with the help of MPN calculator Build 23 by Mike Curiale.

\section{FTIR analysis of soil samples}

\section{Sample preparation}

The infrared spectra were recorded on Thermo Scientific USA. The spectra were scanned in the $400-4000 \mathrm{~cm}^{-1}$ range. The spectra were obtained using potassium bromide $(\mathrm{KBr})$ pellet technique. Potassium bromide (AR grade) was dried under vacuum at $100{ }^{\circ} \mathrm{C}$ for $48 \mathrm{~h}$ and $100 \mathrm{mg}$ of $\mathrm{KBr}$ with $1 \mathrm{mg}$ of sample was taken to prepare $\mathrm{KBr}$ pellet. The spectra were plotted as intensity versus wave number.

\section{Enrichment, purification and culturing of hydrocarbon degrading bacteria}

Petrol and Diesel-oil degrading bacteria were isolated using enrichment containing: $40 \mathrm{ml}$ BBH mineral broth medium supplemented with 1 and diesel and $4.0 \mathrm{~g}$ of contaminated soil. After 2 weeks of incubation at $32^{\circ} \mathrm{C}$, the enriched cultures were serially diluted and inoculated onto BBH agar plates. The lid of Petri-dishes contained $250 \mathrm{ml}$ of sterile diesel-oil as sole source of carbon and energy. Colonies with different morphologies were selected as candidate petroleum hydrocarbon degrading strains and were maintained on standard Nutrient Agar (HiMedia).

\section{Identification of strains}

Genomic DNA of isolates was extracted using lysozyme and proteinase $\mathrm{k}$ method as previously described by many authors. The PCR was carried out with 50-90 ng of pure genomic DNA using the eubacterial primers 27F (5'-AGAGTTTGATCTGGCTCAG-3') and 1492R (5'-GGTTACCTTG TTACGA CTT-3'), located respectively at the extreme $5^{\prime}$ and 3 ' ends of the ribosomal DNA sequence, enable the amplification of nearly the entire gene. The amplification reactions were performed in a $50 \mu \mathrm{L}$ volume by mixing 
template DNA with the polymerase reaction buffer (10x); primers PA and PH (100 ng each) and $0.5 \mathrm{U}$ Taq polymerase. PCR products (approx. $1500 \mathrm{bp}$ ) were purified by PCR purification kit (Qiagen, Valencia, CA). Sequencing was performed by Miniprep kit (Qiagen) and sequenced by using Big Dyeterminator with an automated capillary sequencer (Applied Biosystems) at NBRI, Lucknow. Taxonomic analysis was conducted by the GeneBank basic local alignment search tool (BLAST) program and the gene sequences of analysed strains were deposited in NCBI genebank under accession numbers KX371250-54. The phylogenetic tree (Fig. 4) was inferred using the neighbor-joining method in the MEGA 7 program.

\section{Hydrocarbon degradation potential of isolates}

Identified strains were tested to degrade different hydrocarbons: benzene $\left(\mathrm{C}_{6} \mathrm{H}_{6}\right.$; Cyclohexa-1,3,5-triene), toluene $\left(\mathrm{C}_{7} \mathrm{H}_{8}\right.$; Methyl benzene), naptahlene $\left(\mathrm{C}_{10} \mathrm{H}_{8}\right.$; Bicyclo[4.4.0]deca-1,3,5,7,9-pentene) and acenapthene $\quad\left(\mathrm{C}_{12} \mathrm{H}_{10} ; \quad 1,2\right.$ Dihydroacenaphthylene) (HiMedia) qualitatively as well as quantitatively by two different methods. Out of 22 different looking colonies, 10 isolates were used for checking the degradation of benzene, toluene, naphthalene and acenapthene by the first method. The setup was prepared in $250 \mathrm{ml}$ sterilized conical flasks. Test media contained $50 \mathrm{ml} \mathrm{BBH}$ mineral broth, supplemented with one of the filter sterilized $(0.2 \mu \mathrm{m})$ hydrocarbons $(100 \mathrm{mg} / \mathrm{l})$ and resazurine (10 $\mathrm{mg} / \mathrm{l})$ as a redox indicator. Test solutions were inoculated with $250 \mu \mathrm{l}$ strain culture solutions $\left(\mathrm{OD}_{600}=0.5\right)$. In the case of hydrocarbon degradation the initial blue color of test solution changed to colorless via pink (George Okafor et al., 2009). The test runs were incubated for a week in a rotary shaker at $145 \mathrm{rpm}$ and $28^{0}$ C. Samples with no degradation activity (blue color) were marked "-", minimum microbial activity (bluish pink color) "+", the medium activity pink samples by "++", while samples showing increased hydrocarbon degradation activity (colorless) were marked "+++".

The second method was setup for four time intervals for each identified strain and hydrocarbon. The test media consisted of 20 $\mathrm{ml}$ BBH supplemented with one of the filter sterilized $(0.2 \mu \mathrm{m})$ hydrocarbons at a final concentration of $100 \mathrm{mg} / \mathrm{l}$ for naphthalene and acenapthene whereas $1 \%$ for benzene and toluene. Incubation was done at $35^{\circ} \mathrm{C}$ for 10 , 20, 30 and 40 days at $150 \mathrm{rpm}$. Samples were collected at regular intervals of time and the residual hydrocarbons were extracted according to Vilas Patel et al., (2012) and analyzed by HPLC.

\section{Testing heavy metal and antibiotic resistance of strains}

Heavy metal resistance of strains was tested in nutrient broth containing different concentrations $(0.25,0.5,1.0,2.0,1.0,2.0$, $3.0,4.0,5.0,6.0,7.0,8.0 \mathrm{mM}$ ) of $\mathrm{CdCl}_{2}$, $\mathrm{CuSO}_{4} .5 \mathrm{H}_{2} \mathrm{O}, \quad \mathrm{Pb}\left(\mathrm{NO}_{3}\right)_{2}, \quad \mathrm{ZnSO}_{4} .7 \mathrm{H}_{2} \mathrm{O}$, $\mathrm{MnSO}_{4} \cdot \mathrm{H}_{2} \mathrm{O}, \quad \mathrm{C}_{8} \mathrm{H}_{4} \mathrm{~K}_{2} \mathrm{O}_{12} \mathrm{Sb}_{2} .3 \mathrm{H}_{2} \mathrm{O}$, $\mathrm{SnCl}_{2} .2 \mathrm{H}_{2} \mathrm{O}, \mathrm{K}_{2} \mathrm{Cr}_{2} \mathrm{O}_{7}, \mathrm{NiSO}_{4} \cdot 6 \mathrm{H}_{2} \mathrm{O} \mathrm{HgCl}_{2}$, $\mathrm{FeSO}_{4} .7 \mathrm{H}_{2} \mathrm{O}$ (HiMedia). Stock solutions were prepared in deionized water and were also filter sterilized before inoculation. All tests were done in duplicates and the results were evaluated visually for growth against heavymetal free control cultures and blank tubes.

Sensitivity of selected strains against antibiotics was assayed by the Kirby Bauer's disc diffusion method using Muellere Hinton agar (Bauer et al., 1996; CLSI, 2013). Used antibiotic discs (HiMedia) belonged to the following antibiotic groups: cephalosporins (cefuroxime sodium-CXM30, cefoperazoneCFP75, cefotaxime-CTX30,); tetracyclines 
(tigecycline-TGC15); penicillins (penicillin G-10U, piperacillin-PRL100, amoxyclav-30); quinolones (norfloxacin-NOR10); carbapenems (imipenem-IPM10). Regarding to antibiotic resistance, strains were divided into three groups (resistant-R, intermediate resistant-I, susceptible-S) according to the diameter of the inhibition zone taking into account CLSI interpretive standards (CLSI, 2013).

\section{Results and Discussion}

The $\mathrm{pH}$ of the soil samples varied from 7.57 (HPRB) to 8.5 (KNPP, RJSP, BSP) which is alkaline. The soil temperature varied from 36.2 (KNPP) to 37.5 (CFK). Moisture content was found to be most for HPRB (7.5\%) and least for APR (0.2\%). Inorganic phosphate, nitrate and potassium contents were less when compared to uncontaminated soil standard values. The organic carbon content was high or medium for all the samples except CFK (Table 2).

Total aerobic heterotrophic and hydrocarbon degrading bacteria counts of soil samples

The total heterotrophic count of bacteria was highest in sample sites BROD, HPRR and BSPOCC and least in CFK (Fig. 1). Hydrocarbon degrading bacterial count was less than the total heterotrophic count in most of the samples. In case of benzene degraders the count was maximum for BROD, HPRR, and APR and least for CFK whereas in case of toluene it was highest for BROD, HPRR and BSP and least in CFK (Fig. 2A and 2B). In case of naphthalene degraders the count was maximum for BROD, HPRR, and APR and least for IORR which followed the same trend in case of acenapthene degraders (Fig. $2 \mathrm{C}$ and 2D).

\section{FTIR analysis of soil samples}

From the analysis of FTIR peaks it is clear that all the soil samples contain aromatic compounds other than alkanes, alcohols, phenols, acids, esters and ethers (Table 3). The figures 3A-J gives an idea about the IR spectra of the soil samples.

\section{Taxonomic identification of the bacterial strains}

Characterization carried out has been tabulated in table 4 and table 5.

\section{Hydrocarbon degradation potential}

The aromatic hydrocarbon degradation potential of all the isolates by dye method is shown in table 6 and the percentage degradation calculated after checking the peak area and retention time has been shown in table 7.

\section{Heavy-metal resistance of strains}

Maximum tolerance was shown by Bacillus thuringiensis strain BSPOCC and Aneurinibacillus migulanus strain BROD against antimony $(15 \mathrm{ppm})$ and least was shown by all the five bacterial species against mercury $(0.25 \mathrm{ppm})$. Also all the five species showed good tolerance against lead, zinc and manganese (Table 8).

\section{Antibiotic resistance of strains}

All the identified bacterial species showed resistance against penicillin $\mathrm{G}$ and cefuroxime and were susceptible to impenem, amoxyclav and tigecycline. B. cereus showed resistance or intermediate resistance against 6 out of 9 antibiotics and the other four were resistant only to 2 out of 9 antibiotics used (Table 9). 
Table.1 Soil sampling labels and physicochemical characteristics

\begin{tabular}{|c|c|c|c|c|c|c|c|c|c|}
\hline $\begin{array}{l}\text { Korba } \\
\text { Thermal } \\
\text { Power } \\
\text { Plant }\end{array}$ & $\begin{array}{l}\text { Raigarh } \\
\text { Steel Plant }\end{array}$ & $\begin{array}{l}\text { Bhilai } \\
\text { Steel } \\
\text { Plant }\end{array}$ & $\begin{array}{l}\text { Bhilai } \\
\text { Steel Plant } \\
\text { Oil } \\
\text { Collection } \\
\text { centre }\end{array}$ & $\begin{array}{l}\text { Coal } \\
\text { Field } \\
\text { Korba }\end{array}$ & $\begin{array}{l}\text { Aluminium } \\
\text { Plant } \\
\text { Raigarh }\end{array}$ & $\begin{array}{l}\text { Sponge } \\
\text { Iron } \\
\text { Plant } \\
\text { Urla }\end{array}$ & $\begin{array}{l}\text { Bilaspur } \\
\text { Railway } \\
\text { Oil Depo }\end{array}$ & $\begin{array}{l}\text { HP } \\
\text { Refilling } \\
\text { Raipur }\end{array}$ & $\begin{array}{l}\text { Indian Oil } \\
\text { Refilling } \\
\text { Raipur }\end{array}$ \\
\hline KTPP & RSP & BSP & BSPOCCC & CFK & APR & SIPU & BROD & HPRR & \begin{tabular}{|l|} 
IORR \\
\end{tabular} \\
\hline
\end{tabular}

Table.2 Physico chemical properties of soil samples

\begin{tabular}{|c|c|c|c|c|c|c|c|}
\hline Parameters & pH & $\begin{array}{l}\text { Temp. } \\
\left({ }^{0} \mathrm{C}\right)\end{array}$ & $\begin{array}{l}\text { Moisture } \\
\text { content } \\
(\%)\end{array}$ & $\begin{array}{l}\text { Inorganic } \\
\text { Phospahte } \\
\text { Content } \\
(\mathrm{mg} / \mathrm{L})\end{array}$ & $\begin{array}{l}\text { Nitrate } \\
\text { Content } \\
(\mathrm{mg} / \mathrm{L})\end{array}$ & Available Potassium & $\begin{array}{l}\text { Organic } \\
\text { carbon }\end{array}$ \\
\hline $\begin{array}{l}\text { Uncontaminated } \\
\text { Agricultural soil }\end{array}$ & 7.7 & 35.1 & 9.0 & 922 & 89 & $\begin{array}{l}\text { No line visible very } \\
\text { high above } 392 \mathrm{Kg} / \mathrm{ha}\end{array}$ & Low \\
\hline $\begin{array}{l}\text { Korba Power } \\
\text { Plant (KTPP) }\end{array}$ & 8.5 & 36.2 & 5.0 & 680 & 44 & $\begin{array}{l}\text { No line visible very } \\
\text { high above } 392 \mathrm{Kg} / \mathrm{ha}\end{array}$ & $\begin{array}{l}\text { Medium } \\
\text { High }\end{array}$ \\
\hline $\begin{array}{l}\text { Raigarh Steel } \\
\text { Plant (RSP) }\end{array}$ & 8.5 & 37.1 & 2.1 & 660 & 41 & $\begin{array}{l}\text { No line visible very } \\
\text { high above } 392 \mathrm{Kg} / \mathrm{ha}\end{array}$ & $\begin{array}{l}\text { Medium } \\
\text { High }\end{array}$ \\
\hline $\begin{array}{l}\text { Bhilai Steel } \\
\text { Plant (BSP) }\end{array}$ & 8.5 & 36.4 & 2.5 & 640 & 47 & $\begin{array}{l}\text { No line visible very } \\
\text { high above } 392 \mathrm{Kg} / \mathrm{ha}\end{array}$ & Medium \\
\hline $\begin{array}{lr}\text { Bhilai } & \text { Steel } \\
\text { Plant } & \text { Oil } \\
\text { Collection } & \\
\text { centre } & \\
(\text { BSPOCC) } & \\
\end{array}$ & 7.57 & 36.5 & 7.5 & 590 & 52 & $\begin{array}{l}\text { No line visible very } \\
\text { high above } 392 \mathrm{Kg} / \mathrm{ha}\end{array}$ & High \\
\hline $\begin{array}{l}\text { Coal Field } \\
\text { Korba }(\text { CFK })\end{array}$ & 8.18 & 37.5 & 1.4 & 450 & 49 & $\begin{array}{l}\text { No line visible very } \\
\text { high above } 392 \mathrm{Kg} / \mathrm{ha}\end{array}$ & Low \\
\hline $\begin{array}{l}\text { Aluminium } \\
\text { Plant Raigarh } \\
\text { (APR) }\end{array}$ & 8.36 & 37 & 0.2 & 650 & 46 & $\begin{array}{l}\text { No line visible very } \\
\text { high above } 392 \mathrm{Kg} / \mathrm{ha}\end{array}$ & Medium \\
\hline $\begin{array}{ll}\text { Sponge } & \text { Iron } \\
\text { Plant } & \text { Urla } \\
\text { (SIPU) } & \\
\end{array}$ & 7.84 & 36.5 & 0.3 & 480 & 49 & $\begin{array}{l}\text { Last two line visible: } \\
\text { Medium } 112 \text { to } 280 \\
\mathrm{Kg} / \mathrm{ha}\end{array}$ & $\begin{array}{l}\text { Medium } \\
\text { High }\end{array}$ \\
\hline $\begin{array}{l}\text { Bilaspur } \\
\text { Railway Oil } \\
\text { Depo (BROD) }\end{array}$ & 7.79 & 37.5 & 0.5 & 680 & 40 & $\begin{array}{l}\text { Last two line visible: } \\
\text { Medium } 112 \text { to } 280 \\
\mathrm{Kg} / \mathrm{ha}\end{array}$ & $\begin{array}{l}\text { Medium } \\
\text { Low }\end{array}$ \\
\hline $\begin{array}{ll}\text { HP } & \text { Refilling } \\
\text { Raipur } & \text { (HPRR) }\end{array}$ & 8.4 & 37 & 0.3 & 600 & 54 & $\begin{array}{l}\text { No line visible very } \\
\text { high above } 392 \mathrm{Kg} / \mathrm{ha}\end{array}$ & Low \\
\hline $\begin{array}{l}\text { Indian Oil } \\
\text { Refilling } \\
\text { (IORR) }\end{array}$ & 8.1 & 37.2 & 1.5 & 620 & 49 & $\begin{array}{l}\text { Last two line visible: } \\
\text { Medium } 112 \text { to } 280 \\
\mathrm{Kg} / \mathrm{ha}\end{array}$ & Medium \\
\hline
\end{tabular}


Table.3 FTIR peak analysis

\begin{tabular}{|l|l|l|l|}
\hline Frequency, $\mathbf{c m}^{-\mathbf{1}}$ & Bond & Functional Group & $\begin{array}{l}\text { Soil Samples in which peak } \\
\text { was present }\end{array}$ \\
\hline $3600-3200$ & O-H stretch and & $\begin{array}{l}\text { BROD, CFK, SIPU, APR, } \\
\text { HPRR, KTPP, RSP, BSP, } \\
\text { IORR } \\
\text { Blcohols }\end{array}$ & $\begin{array}{l}\text { BROD, SIPU, BSPOCC, } \\
\text { HPRR, KTPP, RSP }\end{array}$ \\
\hline $1500-1400$ & C-H stretch & Alkanes & $\begin{array}{l}\text { BROD, CFK, SIPU, APR, } \\
\text { BSPOCC, HPRR, KTPP, } \\
\text { RSP, BSP, IORR }\end{array}$ \\
\hline $1320-1000$ & C-C stretch (in-ring) & aromatics & $\begin{array}{l}\text { Alcohols, esters, } \\
\text { acids and ethers } \\
\text { BSPOCCC, HPRR, KTPP, } \\
\text { RSP, BSP, IORR }\end{array}$ \\
\hline $900-675$ & C-O stretch & $\begin{array}{l}\text { BROD, CFK, SIPU, APR, } \\
\text { BSPOCCC, HPRR, KTPP, } \\
\text { RSP, BSP, IORR }\end{array}$ \\
\hline
\end{tabular}

Table.4 Taxonomic identification of the isolated bacterial strains

\begin{tabular}{|c|c|c|c|c|}
\hline \multirow[t]{2}{*}{ Strain } & \multirow{2}{*}{$\begin{array}{lr}\text { Gene } & \text { bank } \\
\text { accession number }\end{array}$} & \multicolumn{2}{|c|}{ Sequence alignment } & \multirow{2}{*}{$\begin{array}{l}\text { Nearest phylogenetic } \\
\text { neighbor } \quad \text { (Gene bank } \\
\text { accession number) }\end{array}$} \\
\hline & & No. of nucleotides & Identity, \% & \\
\hline $\begin{array}{l}\text { Aneurinibacillus } \\
\text { aneuriniliticus } \\
\text { strain RSP }\end{array}$ & KX371250 & 730 & 97 & $\begin{array}{l}\text { Aneurinibacillus } \\
\text { aneuriniliticus strain } \\
\text { NBRC 15521 (NR112639) }\end{array}$ \\
\hline $\begin{array}{l}\text { Aneurinibacillus } \\
\text { migulanus strain } \\
\text { KTPP }\end{array}$ & KX371251 & 1187 & 97 & $\begin{array}{lr}\text { Aneurinibacillus } & \text { migulans } \\
\text { strain NBRC } & 15520 \\
\text { (NR113764) } & \\
\end{array}$ \\
\hline $\begin{array}{l}\text { Aneurinibacillus } \\
\text { migulanus strain } \\
\text { BROD }\end{array}$ & KX371252 & 865 & 98 & $\begin{array}{lr}\text { Aneurinibacillus } & \text { migulans } \\
\text { strain NBRC } & 15520 \\
\text { (NR113764) } & \end{array}$ \\
\hline $\begin{array}{l}\text { Bacillus } \\
\text { thuringiensis strain } \\
\text { BSPOCC }\end{array}$ & KX371253 & 1384 & 99 & $\begin{array}{l}\text { Bacillus } \\
\text { strain ATCC } 10792 \\
\text { (NR114581) }\end{array}$ \\
\hline $\begin{array}{ll}\text { Bacillus } & \text { cereus } \\
\text { strain BSP } & \\
\end{array}$ & KX371254 & 1370 & 99 & $\begin{array}{l}\text { Bacillus cereus strain } \\
\text { ATCC } 14579 \text { (NR074540) }\end{array}$ \\
\hline
\end{tabular}


Table.5 Morphological characteristics of isolates

\begin{tabular}{|l|l|l|l|l|l|}
\hline \multirow{2}{*}{ Characteristics } & \multicolumn{5}{|c|}{ Bacterial isolates } \\
\cline { 2 - 6 } & $\begin{array}{l}\text { Aneurinibacillus } \\
\text { aneuriniliticus } \\
\text { strain RSP }\end{array}$ & $\begin{array}{l}\text { Aneurinibacillus } \\
\text { migulanus strain } \\
\text { KTPP }\end{array}$ & $\begin{array}{l}\text { Aneurinibacillus } \\
\text { migulanus strain } \\
\text { BROD }\end{array}$ & $\begin{array}{l}\text { Bacillus } \\
\text { thuringiensis } \\
\text { strain BSPOCC }\end{array}$ & $\begin{array}{l}\text { Bacillus } \\
\text { cereus } \\
\text { strain BSP }\end{array}$ \\
\hline Colonial characteristics & Circular, white & Circular, white & Circular, white & $\begin{array}{l}\text { Circular, } \\
\text { yellowish }\end{array}$ & $\begin{array}{l}\text { Circular, } \\
\text { white }\end{array}$ \\
\hline Morphological & & & & & \\
\hline Gram's reaction & + & + & + & + & + \\
\hline Shape & Circular & Circular & Circular & Circular & Circular \\
\hline Spore staining & + & + & + & + & + \\
\hline Motility test & + & + & + & + & + \\
\hline Biochemical & & & & & \\
Indole & - & - & - & - & - \\
\hline Methyl red & - & - & - & - & - \\
\hline Voges-Proskauer & + & + & + & + & + \\
\hline Citrate utilization & + & + & + & + & + \\
\hline Catalase & + & + & + & + & + \\
\hline Oxidase & - & - & - & - & - \\
\hline Nitrate reduction & + & + & + & + & + \\
\hline Urease test & - & - & - & - & - \\
\hline Glucose fermentation & + & + & + & + & + \\
\hline Lactose fermentation & + & + & + & + & + \\
\hline Maltose fermentation & - & - & - & - & - \\
\hline Sucrose fermentation & + & + & + & + \\
\hline
\end{tabular}

Table.6 Qualitative hydrocarbon degradation (Dye Method)

\begin{tabular}{|l|l|l|l|l|}
\hline Parameters & \multicolumn{5}{|l|}{ Aromatic hydrocarbon degradation potential } \\
\hline & Benzene & Toluene & Napthalene & Acenapthene \\
\hline B1-KTPP & ++ & ++ & ++ & ++ \\
\hline B2-RSP & ++ & ++ & ++ & ++ \\
\hline B3-BSP & ++ & ++ & ++ & ++ \\
\hline B4-BROD & ++ & ++ & ++ & ++ \\
\hline B5-CFK & - & - & - & - \\
\hline B6-APR & + & + & ++ & ++ \\
\hline B7-SIPU & + & ++ & + & ++ \\
\hline B8-BSPOCCC & ++ & ++ & ++ & ++ \\
\hline B9-HPRR & ++ & ++ & + & + \\
\hline B10-IORR & ++ & + & ++ & + \\
\hline
\end{tabular}

" +++ " results were not obtained as the reaction is reversible in aerobic conditions 
Table.7 Percentage hydrocarbon degradation (By HPLC)

\begin{tabular}{|l|l|l|l|l|}
\hline Bacteria & \multicolumn{3}{|l|}{ Aromatic hydrocarbon degradation potential } \\
\hline & Benzene & Toluene & Napthalene & Acenapthene \\
\hline $\begin{array}{l}\text { Bacillus } \\
\text { thuringiensis strain } \\
\text { BSPOCC }\end{array}$ & $67.8 \%$ & $100 \%$ & $100 \%$ & $82.5 \%$ \\
\hline $\begin{array}{l}\text { Aneurinibacillus } \\
\text { migulanus strain } \\
\text { KTPP cereus }\end{array}$ & $100 \%$ & $100 \%$ & $100 \%$ & $100 \%$ \\
\hline $\begin{array}{l}\text { Bacillus } \\
\text { strain BSP strain }\end{array}$ & $100 \%$ & $98.2 \%$ & $100 \%$ & $73.3 \%$ \\
\hline $\begin{array}{l}\text { Aneurinibacillus } \\
\text { migulanus } \\
\text { BROD }\end{array}$ & $100 \%$ & $91.6 \%$ & $100 \%$ & $55.2 \%$ \\
\hline $\begin{array}{l}\text { Aneurinibacillus } \\
\text { aneurinilyticus } \\
\text { strain RSP }\end{array}$ & $100 \%$ & \\
\hline
\end{tabular}

Table.8 Maximum tolerated concentration (MTC) values of tested heavy metals

\begin{tabular}{|c|c|c|c|c|c|c|c|c|c|c|c|}
\hline \multirow[t]{2}{*}{$\begin{array}{l}\text { Strains } \downarrow \\
\end{array}$} & \multicolumn{9}{|c|}{ MTC values of heavy metals (mM) } & \multirow[b]{2}{*}{ 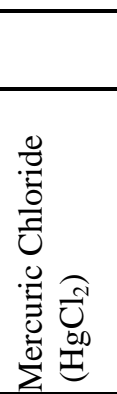 } & \multirow[b]{2}{*}{ 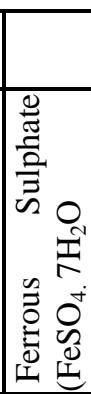 } \\
\hline & 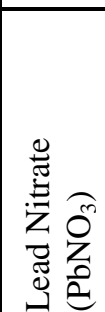 & 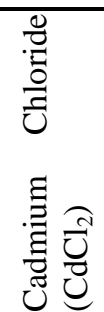 & 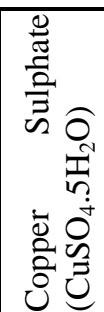 & 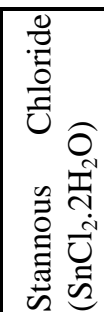 & 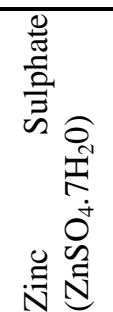 & 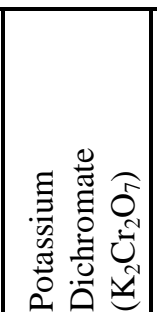 & 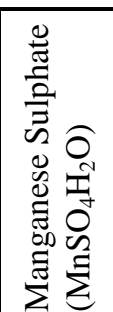 & 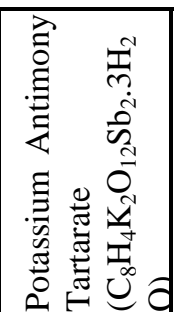 & 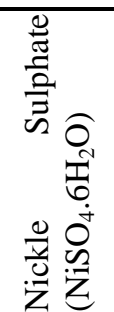 & & \\
\hline $\begin{array}{l}\text { Bacillus cereus } \\
\text { strain BSP }\end{array}$ & 6 & 1 & 4 & \begin{tabular}{|l|}
4 \\
\end{tabular} & 6 & 3 & \begin{tabular}{|l|}
10 \\
\end{tabular} & 6 & 2 & 0.25 & 4 \\
\hline $\begin{array}{l}\begin{array}{l}\text { Bacillus } \\
\text { thuringiensis } \\
\text { strain BSPOCC }\end{array} \\
\end{array}$ & 6 & 0 & 4 & 4 & 6 & 2 & \begin{tabular}{|l|}
10 \\
\end{tabular} & 15 & 1 & 0.25 & 4 \\
\hline $\begin{array}{l}\text { Aneurinibacillus } \\
\text { migulanus strain } \\
\text { BROD }\end{array}$ & 6 & 0 & 4 & 4 & 6 & 2 & \begin{tabular}{|l|}
10 \\
\end{tabular} & \begin{tabular}{|l|}
15 \\
\end{tabular} & 2 & 0.25 & 4 \\
\hline $\begin{array}{l}\text { Aneurinibacillus } \\
\text { migulanus } \text { strain } \\
\text { KTPP }\end{array}$ & 6 & 0 & 4 & 4 & 6 & 2 & 8 & 6 & 6 & 0.25 & 4 \\
\hline $\begin{array}{l}\text { Aneurinibacillus } \\
\text { aneurinilyticus } \\
\text { strain RSP }\end{array}$ & 6 & 0 & 4 & 4 & 6 & 2 & 6 & 6 & 2 & 0.25 & 4 \\
\hline
\end{tabular}


Table.9 Susceptibility of identified strains against antibiotics

\begin{tabular}{|c|c|c|c|c|c|c|c|c|c|}
\hline $\begin{array}{ll}\text { Antibiotic } & \text { and } \\
\text { concentration } \rightarrow & \end{array}$ & 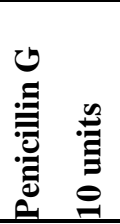 & 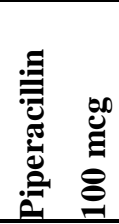 & 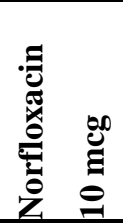 & 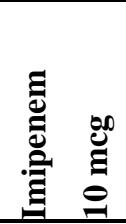 & 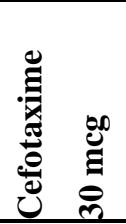 & : & 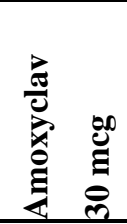 & 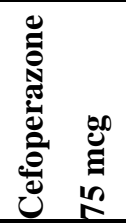 & 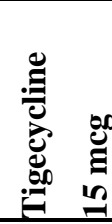 \\
\hline Strains $\downarrow$ & \multicolumn{9}{|c|}{ The average diameter of the inhibition zones ( $\mathrm{mm}$ ) } \\
\hline Bacillus cereus strain BSP & $19(\mathrm{R})$ & $16(\mathrm{R})$ & $16(\mathrm{I})$ & $32(\mathrm{~S})$ & $19(\mathrm{I})$ & $10(\mathrm{R})$ & $26(S)$ & $16(\mathrm{I})$ & $20(\mathrm{~S})$ \\
\hline $\begin{array}{l}\text { Bacillus thuringiensis strain } \\
\text { BSPOCC }\end{array}$ & $24(\mathrm{R})$ & $23(\mathrm{~S})$ & $27(\mathrm{~S})$ & $38(\mathrm{~S})$ & $22(\mathrm{I})$ & $10(\mathrm{R})$ & $29(\mathrm{~S})$ & $26(S)$ & $27(\mathrm{~S})$ \\
\hline $\begin{array}{l}\text { Aneurinibacillus migulanus } \\
\text { strain BROD }\end{array}$ & $21(\mathrm{R})$ & $23(\mathrm{~S})$ & $30(\mathrm{~S})$ & $44(S)$ & $21(\mathrm{I})$ & $14(\mathrm{R})$ & $30(\mathrm{~S})$ & $26(S)$ & $27(\mathrm{~S})$ \\
\hline $\begin{array}{l}\text { Aneurinibacillus migulanus } \\
\text { strain KTPP }\end{array}$ & $22(\mathrm{R})$ & $22(\mathrm{~S})$ & $29(\mathrm{~S})$ & $42(\mathrm{~S})$ & $24(\mathrm{~S})$ & $10(\mathrm{R})$ & $30(\mathrm{~S})$ & $26(S)$ & $29(\mathrm{~S})$ \\
\hline $\begin{array}{l}\text { Aneurinibacillus } \\
\text { aneurinilyticus strain RSP }\end{array}$ & $26(\mathrm{R})$ & $22(\mathrm{~S})$ & $30(\mathrm{~S})$ & $44(S)$ & 20 (I) & $12(\mathrm{R})$ & $30(\mathrm{~S})$ & $26(S)$ & $29(\mathrm{~S})$ \\
\hline
\end{tabular}

R- Resistant; S-Susceptible; I-Intermediate Resistance

Fig.1 Most probable number analysis for the 10 soil samples

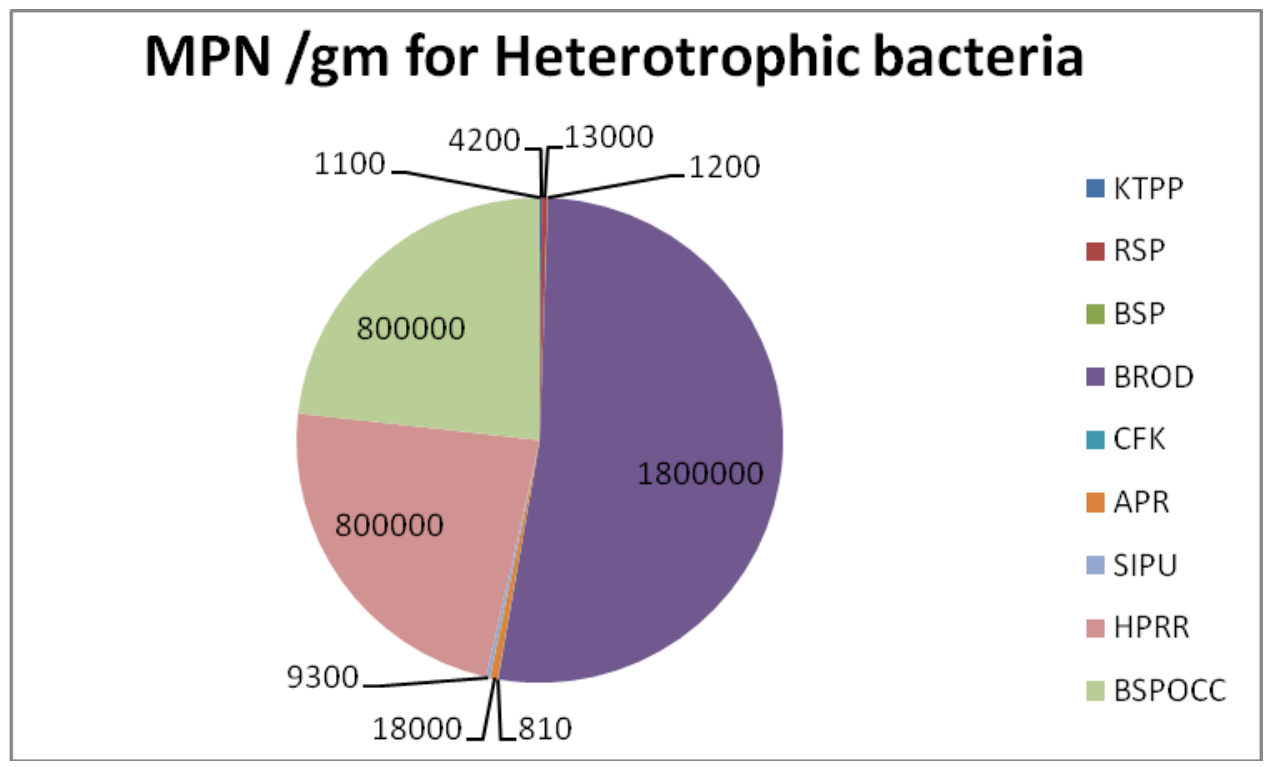


Figure.2 MPN of hydrocarbon degraders

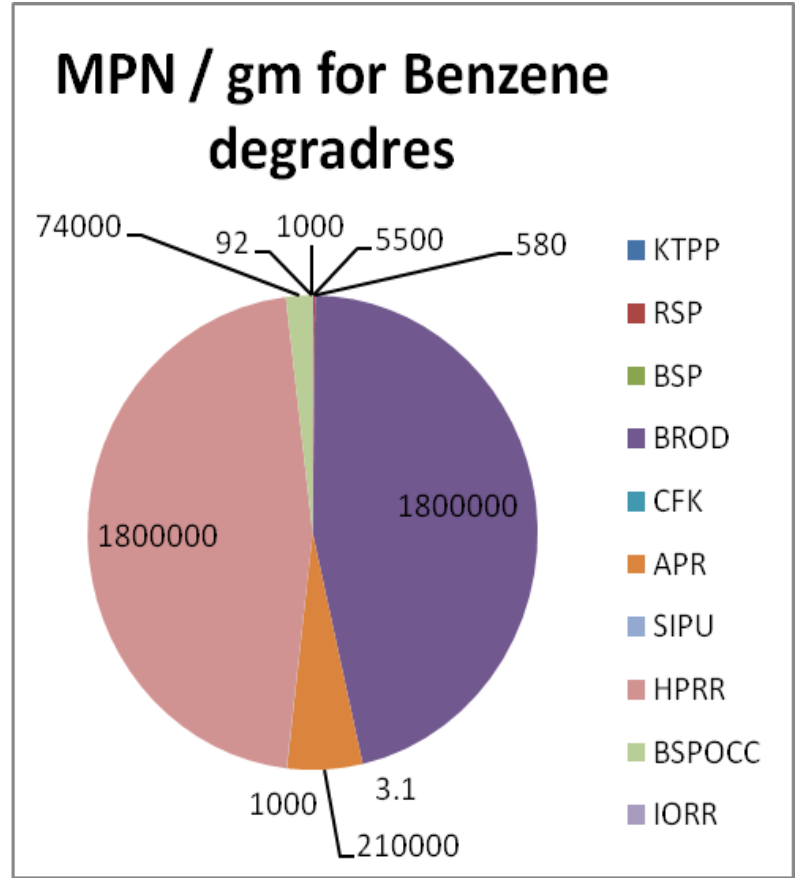

Fig. 2A Most probable number analysis for benzene degraders

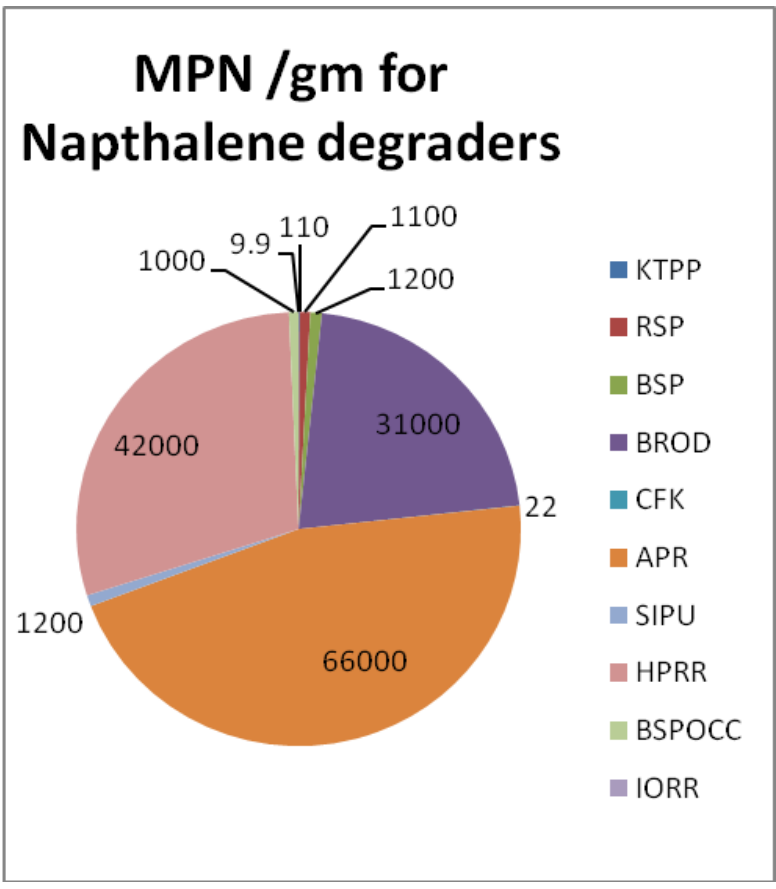

Fig. 2 C: Most probable number analysis for napthalene degraders

\section{MPN / gm for Toluene degraders}

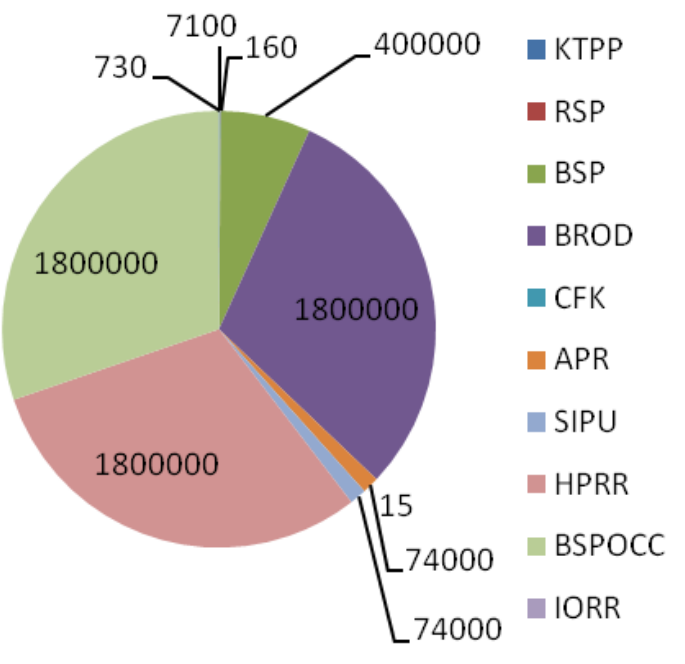

Fig.2 B Most probable number analysis for toluene degraders

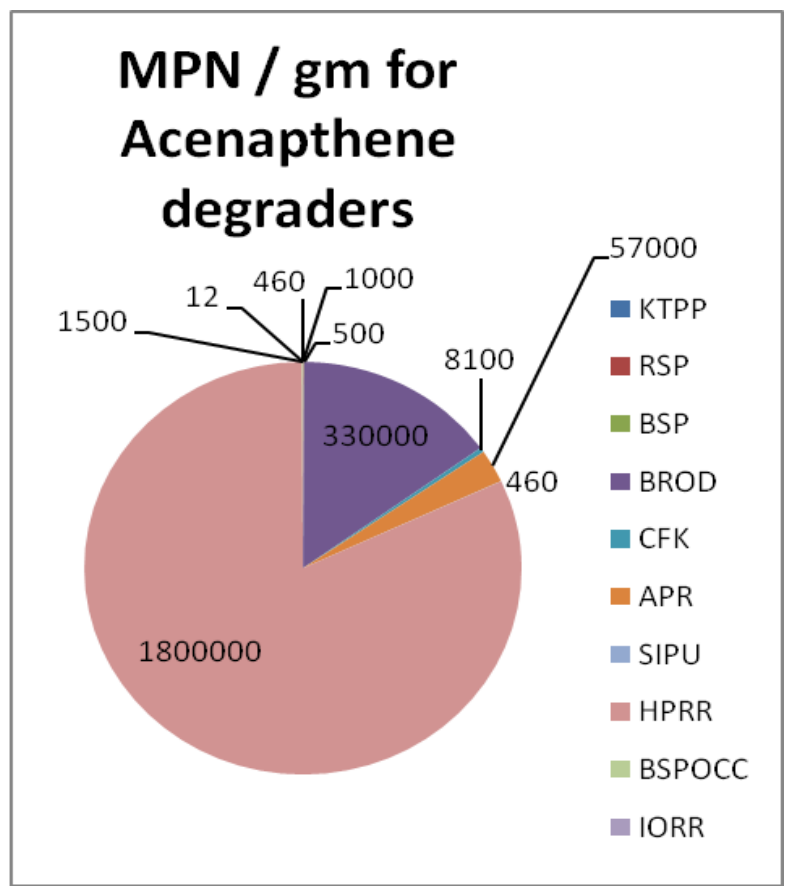

Fig. 2 D Most probable number analysis for acenapthene degraders 
Figure.3 The IR spectra of the soil samples

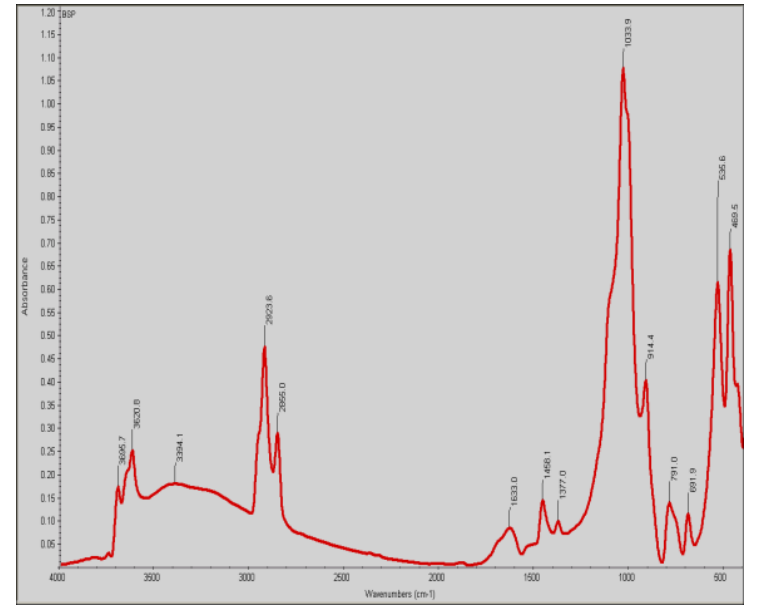

Fig.3A FTIR peaks for soil sample BROD

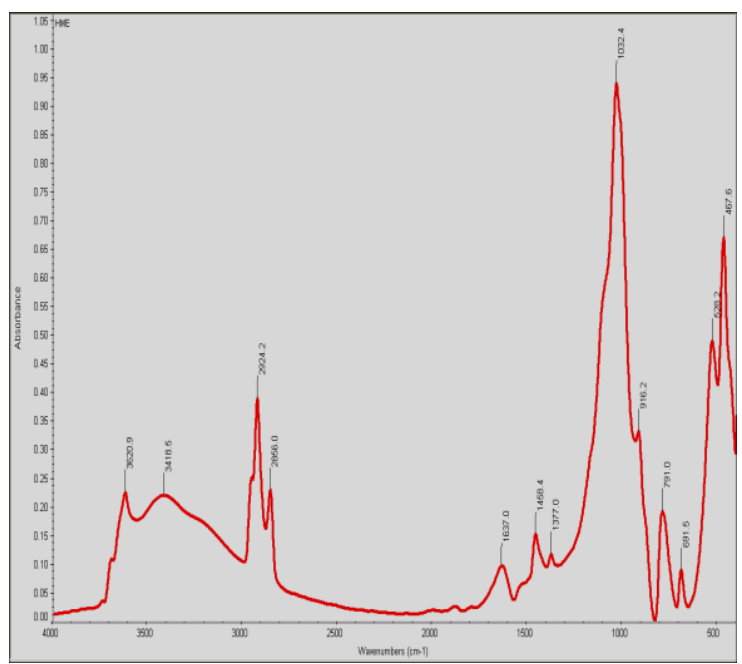

Fig.3C FTIR peaks for soil sample SIPU

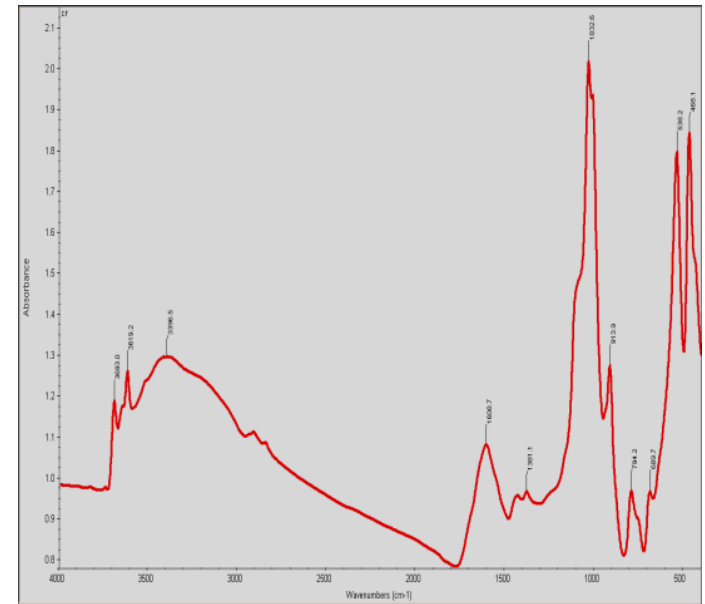

Fig.3B FTIR peaks for soil sample BROD

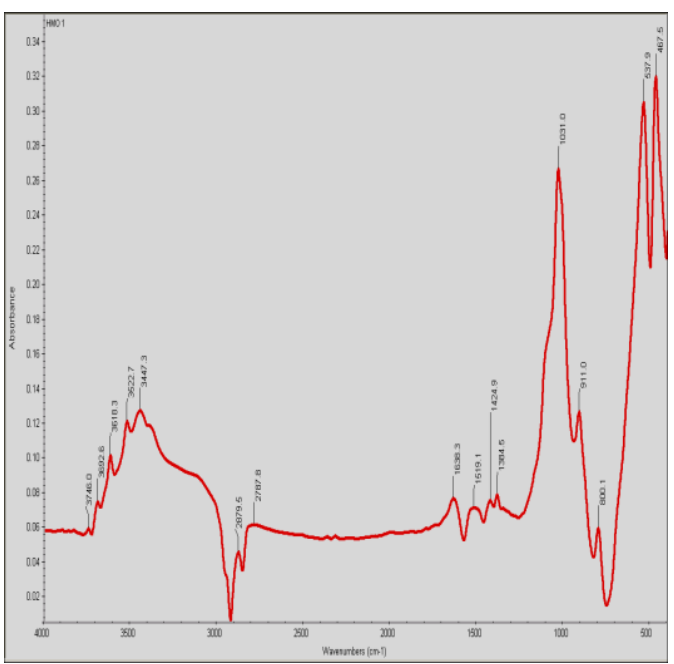

Fig.3D FTIR peaks for soil sample APR 


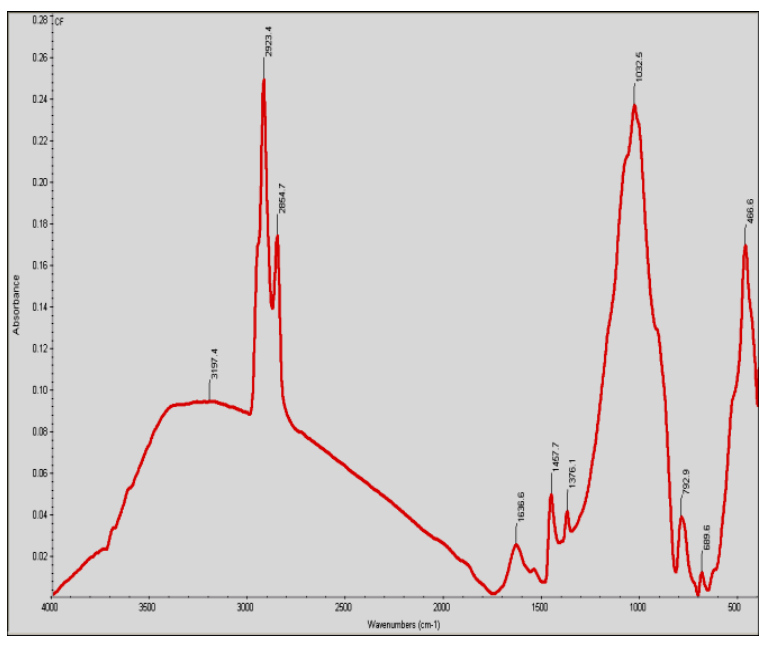

Fig.3E FTIR peaks for soil sample UOS

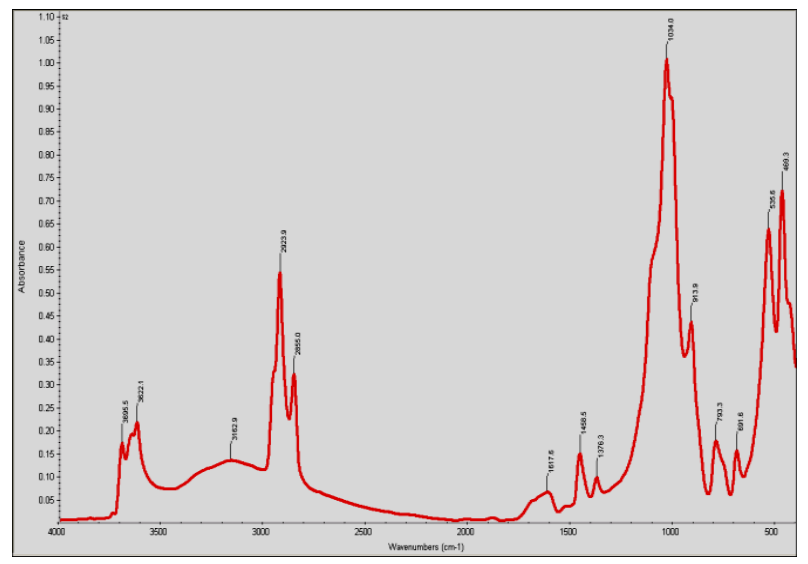

Fig.3G FTIR peaks for soil sample KTPP

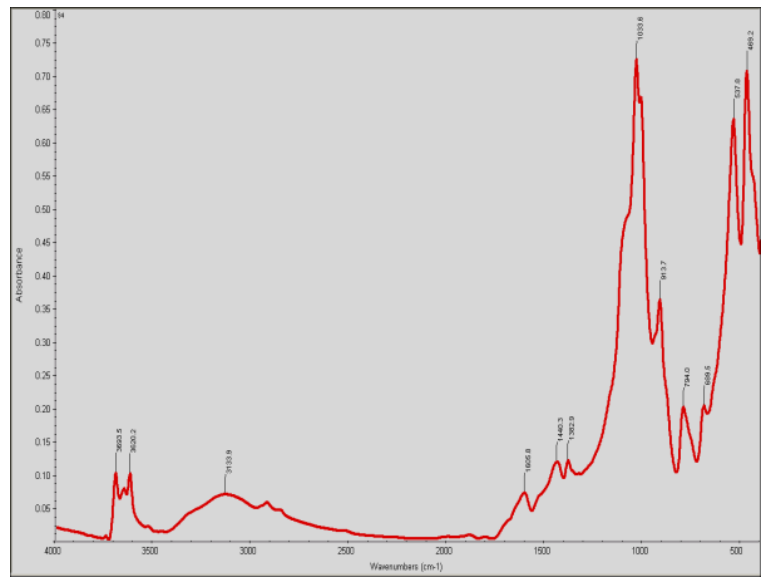

Fig.3I FTIR peaks for soil sample BSP

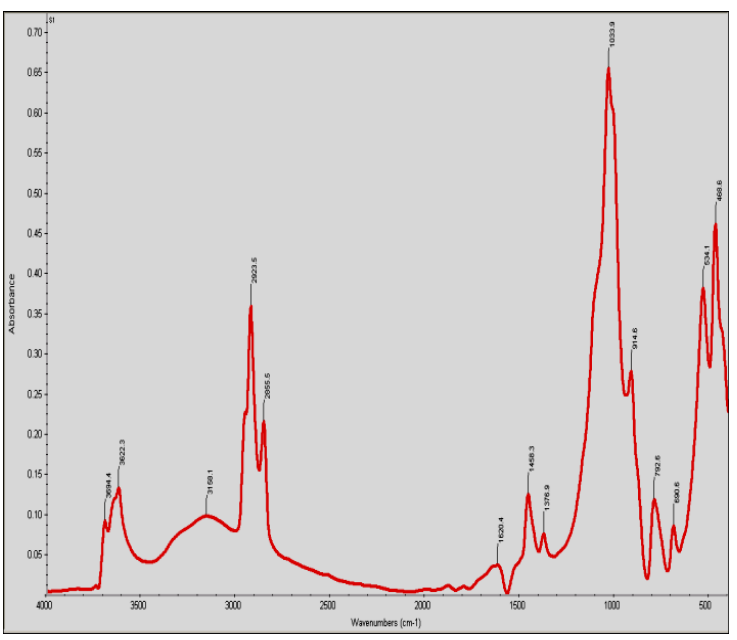

Fig.3F FTIR peaks for soil sample HPRR

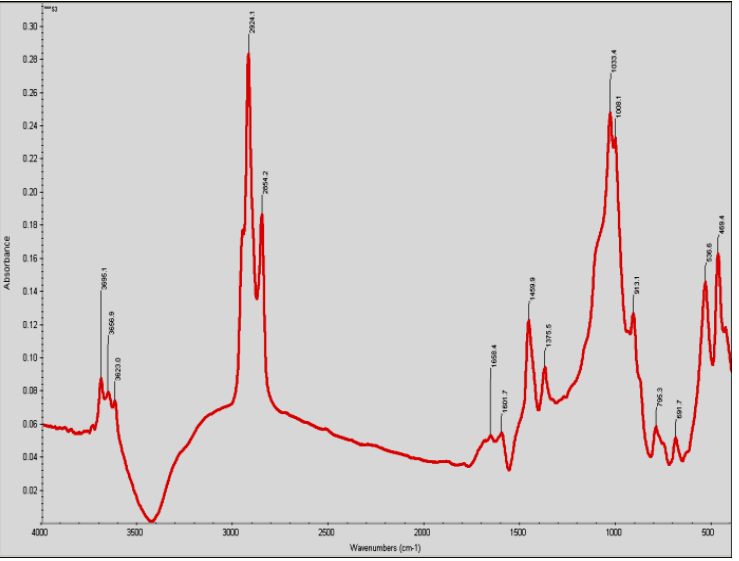

Fig. 3H: FTIR peaks for soil sample RSP

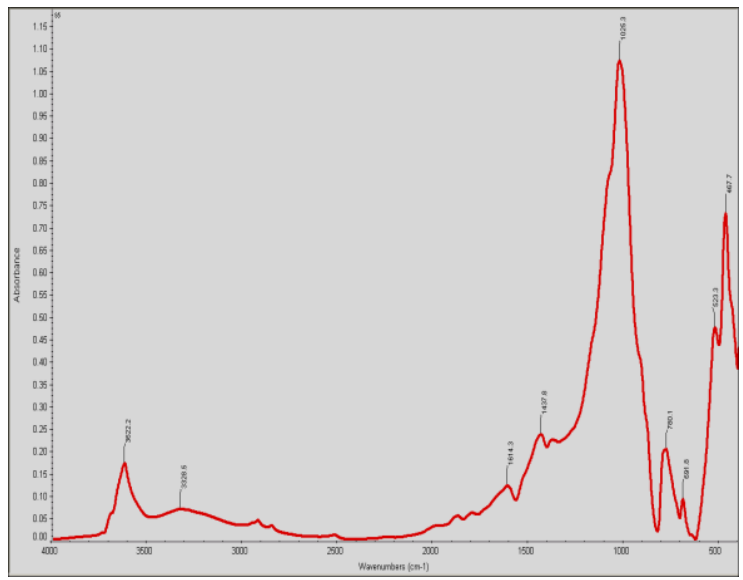

Fig.3J FTIR peaks for soil sample IORR 
Fig.4 Phylogenetic tree derived from 16S rRNA gene sequences showing the relationship between isolates and other species belonging to the genus Bacillus constructed using the neighbor-joining method. Bootstrap values were expressed as percentages of 1000 replications

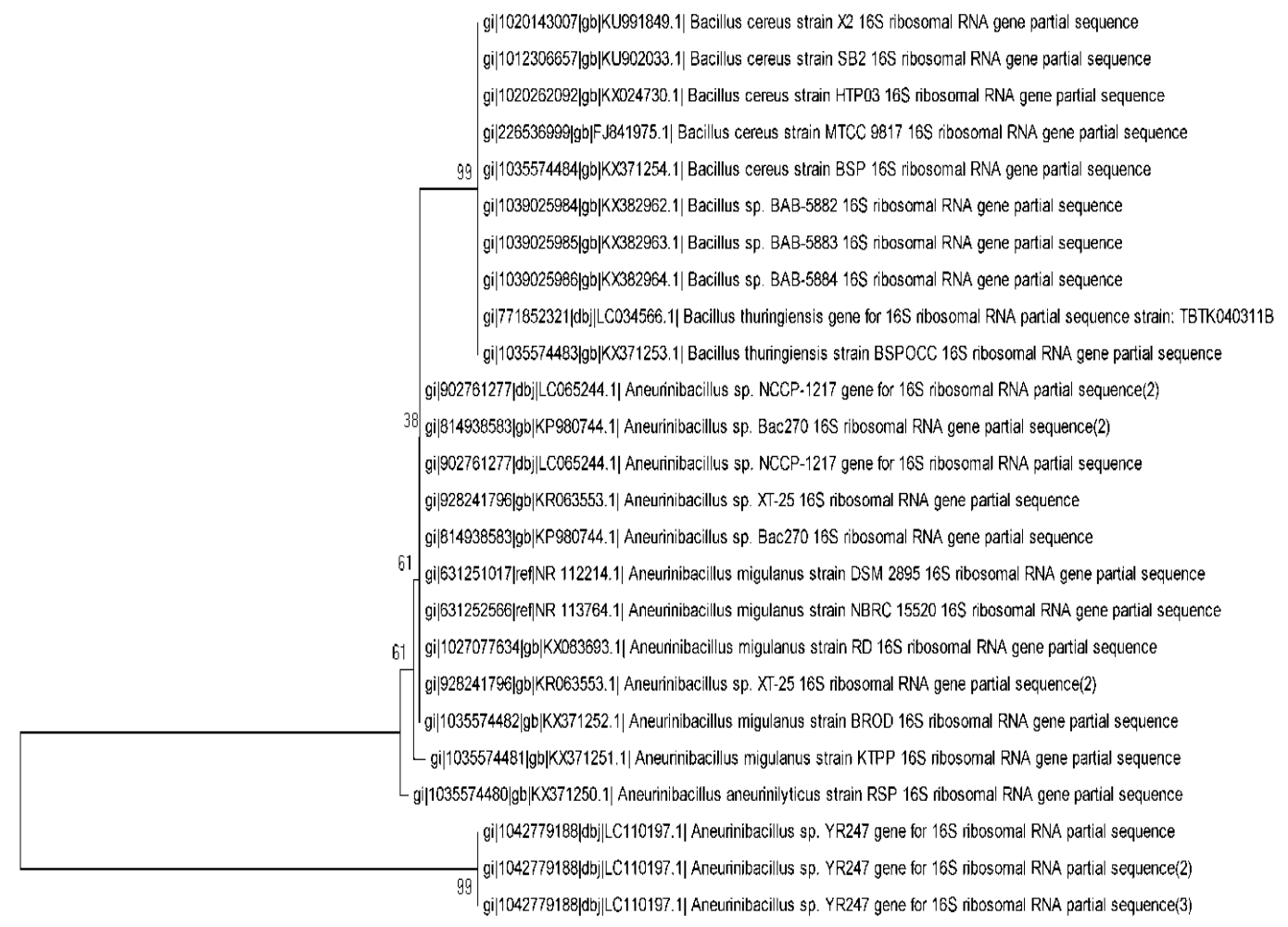

The aim of the study is to obtain a strain collection of hydrocarbonoclastic bacteria, with an outstanding ability to degrade hydrocarbon pollutants and to resist elevated heavy metal concentrations at the same time, for further use in the development of microbial soil inoculants for bioaugmentation purposes. Total ten PHC contaminated soil samples were collected from various locations in Chhattisgarh, India. To check the effect of contamination on different properties of soil, physicochemical analysis of the collected soil samples and one uncontaminated agricultural soil was carried out. PHC pollution exerts adverse effects on soil conditions, microorganisms and plants (Uche et al., 2011), leads to deterioration of soil structure, loss of organic matter contents, loss of soil mineral nutrients such as sodium, calcium, magnesium, nitrogen and sulphate, phosphate and nitrate (Akubugwo et al., 2009). There was no significant change in the $\mathrm{pH}$ of the soils and potassium levels. As expected due to hydrocarbons from the petroleum, the organic carbon content in all the contaminated soil samples was significantly higher than normal soil. The nitrate and phosphate content of the soil samples was less than that of normal soil. Lower concentration of nitrate and phosphate have been reported as limiting factors for the growth of microorganisms in PHC polluted environments (Rahman et al., 2002). The moisture content which determines the extent of water retention and aeration in the soil was also less in PHC contaminated soils as that of normal soil. These two properties are important for the growth of biotic components in the soil. Presence of PHC in the soil increases the soil hydrophobicity (Khamehchiyan et al., 2007, Bennett et al., 1993; Roy et al., 1999), reducing the water holding capacity of the soil (Osuji and Nwoye, 2007). Bundy et al., (2002) have also reported that nutrient balance $(\mathrm{C}$ and 
$\mathrm{N}), \mathrm{pH}$ and moisture content of soil were usually affected as a result of contamination by hydrocarbons. The altered physico-chemical properties of PHC contaminated soil makes it unfit for the growth of agricultural crops as well as the normal soil flora. The soil temperature was slightly higher because of the components present in oil which absorbs light of both the visible and UV range ( $\mathrm{Yu}$ et. al., 2006). Moreover the contaminants in soil form a dark coating which increases the subsurface soil temperature (Balk et. al., 2002). All the samples were found to be slightly alkaline which shows efficient bioremediation (Vidali, 2001).

Identification results of isolated hydrocarbon degrading strains suggested the dominance of the representatives of the Bacillus (Firmicutes) in all the samples. There have been fewer reports on the roles of Bacillus sp. in hydrocarbon bioremediation although there are several reports of bioremediation of pollutants by the action of Bacillus sp. occurring in extreme environments. Sorkhoh et al., (1993) isolated 368 isolates belonging to the genus Bacillus from desert samples. In addition, Annweiller and co-workers (2000) described a B. thermoleovorans that degrades naphthalene at $60{ }^{\circ} \mathrm{C}$. More recently, Ijah and Antai (2003) reported Bacillus sp. being the predominant isolates of all the crude oil utilizing bacteria characterized from highly polluted soil samples.

The MPN count was always higher for heterotrophic bacteria which were supplied with glucose as a sole source of carbon when compared to fuel degrader bacteria which were supplied with either benzene, toluene, naphthalene and acenapthene as sole source of carbon.

Heavy metal resistance of strains was tested in nutrient broth containing different concentrations $(0.25,0.5,1.0,2.0,1.0,2.0,3.0$, $4.0, \quad 5.0, \quad 6.0, \quad 7.0, \quad 8.0 \mathrm{mM})$ of $\mathrm{CdCl}_{2}$, $\mathrm{CuSO}_{4} \cdot 5 \mathrm{H}_{2} \mathrm{O}, \quad \mathrm{Pb}\left(\mathrm{NO}_{3}\right)_{2}, \quad \mathrm{ZnSO}_{4} \cdot 7 \mathrm{H}_{2} \mathrm{O}$, $\mathrm{MnSO}_{4} \cdot \mathrm{H}_{2} \mathrm{O}, \quad \mathrm{C}_{8} \mathrm{H}_{4} \mathrm{~K}_{2} \mathrm{O}_{12} \mathrm{Sb}_{2} \cdot 3 \mathrm{H}_{2} \mathrm{O}$, $\mathrm{SnCl}_{2} \cdot 2 \mathrm{H}_{2} \mathrm{O}, \quad \mathrm{K}_{2} \mathrm{Cr}_{2} \mathrm{O}_{7}, \quad \mathrm{NiSO}_{4} \cdot 6 \mathrm{H}_{2} \mathrm{O} \quad \mathrm{HgCl}_{2}$, $\mathrm{FeSO}_{4} \cdot 7 \mathrm{H}_{2} \mathrm{O}$ (HiMedia). Amongst the tested heavy metals $\mathrm{Pb}^{2+}, \mathrm{Cu}^{2+}, \mathrm{Mn}^{2+,} \mathrm{Sb}^{3+}, \mathrm{Sn}^{2+}$ and $\mathrm{Zn}^{2+}$ were the most tolerated by the tested strains, and the upper limits of tolerance were rallied around a wide range of values $\left(\mathrm{Sn}^{2+}-4\right.$ $\mathrm{mM}$ to $\left.\mathrm{Sb}^{3+}-15 \mathrm{mM}\right)$. The presence of $\mathrm{Cd}^{2+}$, $\mathrm{Cr}^{2+}$ and $\mathrm{Hg}^{2+}$ was very sensitive to all the isolates. The presence of $\mathrm{Ni}^{2+}$ had an inhibitory effect on all the isolates except Aneurinibacillus migulans strain KTPP. Outstanding ability of Bacillus species in remediation of heavy metals has been demonstrated in various studies (Ferdag et al., 2011; Ersoy et al., 2009; Othman and Thoufeek 2015; Yogendra et al., 2013).

B. cereus showed resistance / intermediate resistance against 6 of the 9 antibiotics whereas rest of the isolates showed resistance only against 2 antibiotics (Penicillin and Cefuroxime). Multiple resistance against heavy metals and antibiotics of $B$. cereus isolates has also been reported by Singh et al. (2010). Since several genes responsible for degradation of aromatics and for heavy metal/antibiotic resistances are located on plasmids which are key vectors of horizontal gene transfer, the members of the bacterial community gained opportunity to expand their chromosome encoded resistance and catabolic potential with those encoded on plasmids. This phenomenon may explain the strong correlation among hydrocarbon degradation ability and heavy metal/antibiotic tolerance among strains. In case of strains isolated from the solely PHC impacted sample the lack of correlation among foregoing capabilities might be linked to the lack or low rate of transmission of mobile genetic elements. In the absence of a strong driving force (e.g. presence of heavy metals or antibiotics) the endogenous micro biota is not actuated for the exchange of resistance carrying plasmids. Our findings justify the above statement that in the absence of antibiotic driving force in the environment around soil sample collected caused the partial gene transfer for heavy metal resistance only and not for antibiotic resistance. Furthermore, as several biodegradative pathways are located also on mobile genetic elements, a long term exposure to heavy metals/antibiotics may be linked to the 
widespread distribution of biodegradative capabilities as well (Roy et al., 2002). Nevertheless, the lack or complete/partial loss of these transmissible genetic segments may lead to the reduced degradative functions, as well as to the loss of multiple resistances (Amábile-Cuevas et al., 1991; Marqués and Ramos, 1993).

\section{Acknowledgement}

This work was supported in part by the CSIR laboratories (National Botanical Research Institue and Indian Toxicology Research Centre, Lucknow). I sincerely acknowledge all the faculties and scholars from Department of Biotechnology, Babasaheb Bhimrao Ambedkar University, Lucknow for their supportive role in accomplishing my research work.

\section{References}

Abdullah, M.Z.B., Saat, A.B., Hamzah, Z.B., 2011. Assessment of the impact of petroleum and petrochemical industries to the surrounding areas in Malaysia using mosses as bioindicator supported by multivariate analysis. Environ. Monitoring and Assessment.

Akubugwo, E.I., Ogbuji, G.C., Chinyere, C.G. and Ugbogu, E.A. 2009. Physicochemical properties and enzymes activity studies in a refined oil contaminated soil in Isiukwuato, Abia state, Nigeria. Biokemistri, 21: 79-84.

Alzahrani, O., Ahamed T., 2015. Isolation and Characterization of Heavy Metal Resistant Bacillus subtilis spp. Collected from Water Sources of Taif Province of Saudi Arabia. Int. J. Curr. Microbiol. App. Sci., 4(6): 350-357

Amábile-Cuevas, C.F., Piña-Zentella, R., WahLaborde, M.E., 1991. Decreased resistance to antibiotics and plasmid loss in plasmid-carrying strains of Stahpylococcus aureus treated with ascorbic acid. Mutation Res., 264: 119125.

Annweiller, E., Richnow, H.H., Antranikian,
G., Hebenbrock, S., Garms, C., Franke, S., Francke, W., Michaelis, W., 2000. Naphthalene degradation and incorporation ofnaphthalene-derived carbon into biomass by the thermophile Bacillus thermoleovorans. Appl. Environ. Microbiol., 66: 518-523.

Balks, M.R., Paetzold, R.P., Kimble, J.M., Aislabie, J., Campbell, I.B., 2002. Effects of hydrocarbon spills on the temperature and moisture regimes of Cryosols in the Ross Sea region. Antarct. Sci., 14: 319326.

Bauer, A.W., Kirby, W.M.M., Sherris, J.C., Turck, M., 1996. Antibiotic susceptibility testing by a standardized single disc method. American J. Clin. Pathol., 45: 493-496.

Bennett, P.C., Siegel, D.E., Baedecker, M.J., 1993. Crude oil in a shallow sand and gravel aquifer-I. Hydrogeology and inorganic geochemistry. Appl. Geochem., 8(6): 529-549.

Braddock, J.F., Catterall, P.H., 1999. A simple method for enumerating gasoline and diesel-degrading microorganisms. Bioremediation J., 3: 81-84.

Bundy, J. G., Paton, G. I. and Campbell, C. D., 2002. Microbial communities in different soil types do not converge after diesel contamination. J. Appl. Microbiol., 92: 276-288.

CLSI. 2013. Performance Standards for Antimicrobial Susceptibility Testing. CLSI Approved Standard M100-S17. Clinical and Laboratory Standards Institute, Wayne, PA.

Colak, F., Atar, N., Yazicioglu, D., Olgun, A., 2011. Biosorption of lead from aqueous solutions by Bacillus strains possessing heavy-metal resistance. Chemical Engineering J., Volume 173, Issue 2; 422-428

Damian, F., Damian, G., Lacatus U.R., Iepure, G., 2008. Heavy metals concentration of the soils around Zlatna and Cops, aMic_a smelters Romania. Carpathian J. Earth and Environ. Sci., 3: 65-82.

George-Okafor, U., Tasie, F., Muotoe-Okafor, 
F. 2009. Hydrocarbon degradation potentials of indigenous fungal isolates from petroleum contaminated soils. $J$. Physical and Natural Sci., 3: 1-6.

Hooda, S., Kaur, S. 1999. Laboratory manual for environmental Chemistry. S. Chand and Company Ltd., New Delhi.

Ijah, U.J.J., Antai, S.P., 2003. Removal of Nigerian light crude oil in soil over a 12month period. Int. Biodeterioration and Biodegradation, 51: 93-99.

John, N.M., 2007. Heavy metals content of crude oil sludge/poultry manure and crude oil sludge/municipal solid waste composts. Agricultural J., 2: 281-284.

Khamehchiyan, M., Hossein, Charkhabi, A., Tajik, M., 2007. Effects of crude oil contamination on geotechnical properties of clayey and sandy soils. Engineering Geol., 89(3): 220-229.

Knapp, C.W., McCluskey, S.M., Singh, B.K., Campbell, C.D., Hudson, G., Graham, D.W., 2011. Antibiotic resistance gene abundances correlate with metal and geochemical conditions in archived Scottish soils. PLoS One.

Marqués, S., Ramos, J.L., 1993. Transcriptional control of the Pseudomonas putida TOL plasmid catabolic pathways. Molecular Microbiol., 9: 923-929.

Mishra, S., Dwivedi, S.P., Singh, R.B., 2010. A reviewon epigenetic effect of heavy metal carcinogens on human health. The Open Nutraceuticals J., 3: 188-193.

Mrozik, A., Piotrowska-Seget, Z., 2009. Bioaugmentation as a strategy for cleaning up of soils contaminated with aromatic compounds. Microbiological Res., 165: 363-375.

Muntean, A., Rusu, T., 2011. The nitrogen regime in arable soils under the influence of tailings from mining landfills in the urban perimeter of Baia Mare. Bulletin UASVM Agri., 68: 101-107.

Osuji, L. and Nwoye, I. 2007. An appraisal of the impact of petroleum hydrocarbons on soil fertility: the Owaza experience. Afr. J. Agric. Res., 2: 318-324.

Osuji, L.C., Onojake, C.M., 2004. Trace heavy metals associated with crude oil: a case study of Ebocha-8 oil-spill-polluted site in Niger Delta, Nigeria. Chemistry and Biodiversity, 11: 1708-1715.

Patel, V., Jain, S. and Madamwar, D. 2012. Napthalene degradation by bacterial consortium (DV-AL) developed from Alang-Sosiya ship breaking yard, Gujrat, India Bioresource Technol., 107: 122130.

Rahman, K.S., Banat, I.M., Thahira, J., Thayumanavan, T. and Lakshmanaperumalsamy, P. 2002 Bioremediation of gasoline contaminated soil by a bacterial consortium amended with poultry litter, coir pith and rhamnolipid biosurfactant. Bioresour. Technol., 81: 25-32.

Roy, J.L., McGill, W.B., Rawluk, M. D., 1999. Petroleum residues as water-repellent substances in weathered nonwettable oilcontaminated soils. Canadian J. Soil Sci., 79(2): 367.

Roy, S., Hens, D., Biswas, D., Kumar, R., 2002. Survey of petroleum degrading bacteria in coastal waters of Sunderban Biosphere Reserve. World J. Microbiol. Biotechnol., 18: 575-581.

Sarkar, D., Ferguson, M., Datta, R., Birnbaum, S., 2004. Bioremediation of petroleum hydrocarbons in contaminated soils: comparison of biosolids addition, carbon supplementation, and monitored natural attenuation. Environmental Pollu., 136: 187-195.

Sevgi, E., Coral, G., Gizir, A.M., Sangün, M.K., 2010. Investigation of heavy metal resistance in some bacterial strains isolated from industrial soils. Turkish $J$. Biol., 34: 423-431.

Singh, S.K., Tripathi, V.R., Jain, R.K., Vikram, S., Garg, S.K., 2010. An antibiotic, heavy metal resistant and halotolerant Bacillus cereus SIU1 and its thermoalkaline protease. Microbial Cell Factories, 9.

Singh, Y., Ramteke, P.W., Tripathy, A., Shukla, P.K., 2013. Isolation and Characterization of Bacillus resistant to multiple heavy metals. Int. J. Curr. Microbiol. App. Sci., 2(11): 525-530 
Sorkhoh, N.A., Al-Hasan, R.H., Khanafer, M., Radwan, S.S., 1995. Establishment ofoildegrading bacteria associated with cyanobacteria in oil-polluted soil. J. Appl. Bacteriol., 78: 194-199.

Trindade, P.V.O., Sobral, L., Rizzo, A.C.L., Leite, S.G.F., Soriano, A., 2004. Bioremediation of a weathered and a recently oil-contaminated soils from Brazil: a comparison study. Chemosphere, 58: 515-522

Uche, O.M., Owhondah, W.M. and Augustine, U.A. 2011. The Omoku old pipeline oil spill: Total hydrocarbon content of affected soils and the impact on the nutritive value of food crops. Archiv. Appl. Sc. Res., 3: 514-521.
Vidali, M. 2001. Bioremediation: An overview. Pure Appl. Chem., 73(7): 1163-1172

Wolicka, D., Suszek, A., Borkowski, A., Bielecka, A., 2009. Application of aerobic microorganisms in bioremediation in situ of soil contaminated by petroleum products. Biores. Tech., 100: 3221-3227.

Yu, H., Xia, Q., Yan, J., Saenz, D.H., Wu, Y. S., Tang, W. and Fu, P.P. 2006. Photoirradiation of Polycyclic Aromatic Hydrocarbons with UV-A Light-A Pathway Leading to the Generation of Reactive Oxygen Species, Lipid Peroxidation, and DNA Damage, Int. J. Environ. Res. Public Health, 3(4): 348354.

\section{How to cite this article:}

Jai Godheja, Sudhir K. Shekhar, G.N.V. Satyanarayan, Satyendra Pratap Singh and Dinesh Raj Modi. 2017. Antibiotic and Heavy Metal Tolerance of Some Indigenous Bacteria Isolated From Petroleum Contaminated Soil Sediments with A Study of Their Aromatic Hydrocarbon Degradation Potential. Int.J.Curr.Microbiol.App.Sci. 6(3): 194-211. doi: https://doi.org/10.20546/ijcmas.2017.603.021 